\section{Hematological Monitoring During Therapy with Carbamazepine in Children}

Faye S. Silverstein, MDCM, ${ }^{*}$ Lawrence Boxer, MD, $\dagger$ and Michael V. Johnston, $\mathrm{MD}^{*}$

Carbamazepine (CBZ) is being prescribed more frequently for treatment of children and adults with generalized tonicclonic and partial complex seizures. Early reports of aplastic anemia in elderly patients treated with this drug led to concern about its potential hematological toxicity. A variety of other hematological abnormalities have also been described in association with $\mathrm{CBZ}$ therapy, including agranulocytosis, thrombocytopenia, and transient leukopenia. The drug labeling recommends frequent blood tests and includes strict guidelines for discontinuation of therapy if relatively minor abnormalities occur, for example, total white blood cell count (WBC) less than 4,000 per cubic millimeter. Several authors have questioned the validity and practicality of these guidelines [1]. In fact, routine monitoring is not practiced at certain epilepsy centers. The major objection raised is that routine monitoring does not help predict which patients will develop severe idiosyncratic drug reactions.

It has been suggested that children are less likely than adults to develop hematological abnormalities while receiving CBZ therapy, but few large pediatric series have been reported. To determine the incidence and severity of hematological problems associated with $\mathrm{CBZ}$, we reviewed the records of 200 children who attended the Pediatric Neurology Clinic at the University of Michigan Medical Center from 1978 to 1982 [4]. We compared two groups of patients. Group 1 consisted of 125 children in whom therapy was initiated before age 12 ( 39 were less than 6 years old); group 2 included 75 children who were between 12 and 17 years old at the start of therapy. Mean duration of treatment (18 months), mean CBZ level $(6 \mu \mathrm{g} / \mathrm{ml})$, and mean number of other anticonvulsants (1.5) were the same for the two groups. No patient developed any symptomatic hematological problem.

The Table summarizes the results of hematological surveillance in these children. Leukopenia (WBC less than 4,000 per cubic millimeter) was the most frequently noted abnormality and was almost twice as common in the younger age group. In most patients leukopenia resolved while CBZ therapy was continued, but 4 of the 200 had persistent or recurrent leukopenia while taking the drug. The drug was discontinued in 3 patients because of leukopenia. There was no detectable clinical difference between the patients in whom the drug was stopped and those for whom the decision was made to continue treatment.

Based on our experience and published series [3], it appears that $C B Z$ is a relatively safe drug for children with seizures. However, although it is possible that leukopenia was sometimes unrelated to $\mathrm{CBZ}$, its occurrence in a minority of patients merits further investigation and suggests that hematological surveillance is appropriate. Although reports in the literature are inconsistent about the value of routine blood counts in preventing or altering the outcome of
Hematological Abnormalities in Cbildren Treated with Carbamazepine for Seizures

\begin{tabular}{lll}
\hline Abnormality & $\begin{array}{l}\text { No. in Group 1 } \\
(\mathrm{n}=125)^{\mathrm{a}}\end{array}$ & $\begin{array}{l}\text { No. in Group 2 } \\
(\mathrm{n}=75)^{\mathrm{b}}\end{array}$ \\
\hline $\begin{array}{l}\text { Hgb }<12 \mathrm{gm} \\
\text { WBC }<4,000 / \mathrm{mm}^{3}\end{array}$ & 0 & 0 \\
$\begin{array}{l}\text { WBC }<4,000 / \mathrm{mm}^{3} \\
3 \text { mo or longer }\end{array}$ & 4 & $6(8 \%)$ \\
Platelets $<200,000$ & 2 & 0 \\
\hline
\end{tabular}

aAge range, 1 to 11 years.

${ }^{\mathrm{b}}$ Age range, 12 to 17 years.

$\mathrm{Hgb}=$ hemoglobin; WBC $=$ white blood cell count.

idiosyncratic drug-related aplastic anemia, reputable authorities do recommend monitoring, especially for newer drugs [2]. The justifications for monitoring with CBZ therapy include early identification of patients developing potentially reversible symptomatic neutropenia or agranulocytosis, accumulation of more information about the natural history of drug-related leukopenia, and, possibly, early identification of patients developing aplastic anemia.

The available data are insufficient to indicate the mechanism of neutropenia [5] or to support a particular schedule of laboratory testing. We suggest the following guidelines as a practical minimum:

1. Hemoglobin, hematocrit, WBC, and platelet estimate be fore therapy, monthly for six months, and then every three months.

2. If total WBC falls to less than 4,000 per cubic millimeter, neutrophil, platelet, and reticulocyte counts.

3. If neutrophil count falls to 1,000 to 1,500 per cubic millimeter and the patient is well, repeat in two weeks; if still in this range, consider discontinuing therapy unless strongly indicated. If neutrophil count drops below 1,000 per cubic millimeter, decrease dosage or discontinue drug and repeat count in two weeks.

4. If, in addition to neutropenia, there is a depression in platelet or reticulocyte count, hematological consultation is advisable.

Presented at the Eleventh Annual Meeting of the Child Neurology Society, Salt Lake City, UT, October 7-9, 1982.

* Departments of Pediatrics and Neurology

Section of Pediatric Neurology and

†Section of Pediatric Hematology-Oncology

University of Michigan Medical Center

Ann Arbor, MI 48109

\section{References}

1. Hart RG, Easton JD: Carbamazepine and hematological monitoring. Ann Neurol 11:309-312, 1982

2. Heimpel $\mathrm{H}$, Hert $\mathrm{W}$ : Drug-induced aplastic anemia: clinical aspects. Clin Haematol 9:641-662, 1980

3. Huf R, Schain RJ: Long term experience with carbamazepine (Tegretol) in children with seizures. J Pediatr 97:310-312, 1978 
4. Silverstein FS, Parrish MA, Johnston MV: Adverse reactions to carbamazepine (Tegretol) in children with epilepsy (abstract). Ann Neurol 12:198, 1982

5. Young GAR, Vincent PC: Drug-induced agranulocytosis. Clin Haematol 9:483-504, 1980

\section{Familial Periodic Paralysis: Low Muscle Potassium Permeability or High Sodium Permeability?}

\author{
J. J. Schipperheyn, $\mathrm{MD}, \mathrm{PhD}$,* \\ and O. J. S. Buruma, MD, $\mathrm{PhD}^{\dagger}$
}

The recent article in the Annals on periodic paralysis and the sodium potassium pump by Robert B. Layzer [5] ends with a provocative attempt to postulate a single membrane abnormality that accounts for the attacks of inexcitability of skeletal muscle in familial periodic paralysis. It would be satisfying indeed to demonstrate that a single pinpoint lesion of the membrane could lead to such an impressive symptom.

Layzer's hypothesis is based on the assumption that attacks are induced by the low extracellular potassium $\left([\mathrm{K}]_{0}\right)$ concentration that is either caused locally in affected muscles or generalized in the whole body by overactivity of the Na-K pump during periods of rest. Inexcitability results, according to this hypothesis, from depolarization of the membrane caused by a decrease in permeability to potassium $\left(\mathrm{P}_{\mathrm{K}}\right)$. The $P_{K}$ is lowered, supposedly, by the effect of the low $[K]_{10}$ on the potassium permeability of the membrane. By itself the decrease in $\mathrm{P}_{\mathrm{K}}$ can increase the membrane potentials to values above $-50 \mathrm{mV}$, enough to inactivate fast sodium transport. Layzer supposes that, as in cases of barium poisoning, membrane voltage can be temporarily maintained close to its normal level by the electrogenic part of the $\mathrm{Na}-\mathrm{K}$ pump, its effect enhanced by the increased membrane resistance.

Apart from the fact that the hypothesis fails to explain why paresis develops before $[\mathrm{K}]_{\mathrm{o}}$ is lowered, it is not in keeping with pertinent observations made by a number of investigators. Most direct measurements of membrane voltage have revealed that during attacks the membrane is inexcitable but nevertheless not or only slightly depolarized $[4,6,7,8]$, and rarely depolarized far enough to fully inactivate fast sodium transport. Moreover, direct measurements of total membrane resistance are consistent with an increase in $\mathrm{P}_{\mathrm{K}}$ rather than with a reduction. From the simplified Hodgkin and Katz equations [3] valid for steady-state conditions, it can be calculated that for $\mathrm{P}_{\mathrm{Na}} / \mathrm{P}_{\mathrm{K}}$ ratios above 0.05 , membrane potential is practically constant for all practical values of $[\mathrm{K}]$. below $4.5 \mathrm{mmol} / \mathrm{L}$. All this evidence supports the hypothesis that during attacks $P_{\mathrm{Na}}$ increases and not that $P_{K}$ decreases. In this respect it is interesting that procaine, which selectively blocks sodium transport, partly restores excitability [4].

The assumption that $\mathrm{P}_{\mathrm{Na}}$ is raised is in agreement with observations pointing to a cell-inward transport of water and
$\mathrm{Na}$ and $\mathrm{Cl}$ ions early during attacks. The presence of $\mathrm{Na}$ ions at the inner surface of the membrane always strongly stimulates active $\mathrm{Na}-\mathrm{K}$ transport, which can lower serum potassium levels rapidly. As Layzer states [5], it would not be difficult to construct another hypothetical scheme based on high $\mathrm{P}_{\mathrm{Na}}$. A high $\mathrm{P}_{\mathrm{Na}}$ seems more in keeping with the experimental data than does a low $\mathrm{P}_{\mathrm{K}}$. A high $\mathrm{P}_{\mathrm{Na}}$, however, does not automatically explain the inactivation of fast $\mathrm{Na}$ transport.

Therefore, the scheme needs to be expanded. Poisoning of the muscle membrane by a venom extracted from the scorpion centruroides sculpturatus provides an interesting model for familial periodic paralysis. This venom not only blocks fast $\mathrm{Na}$ transport, as does tetrodotoxin, but simultaneously increases resting $\mathrm{P}_{\mathrm{Na}}[1]$. The resulting changes in membrane properties closely parallel the observed changes during attacks of periodic paralysis. Scorpion venom is a polypeptide, and one can easily complete the high $\mathrm{P}_{\mathrm{Na}}$ scheme by postulating an inborn error of cellular protein metabolism that occasionally leads to the synthesis of a toxic polypeptide. The sensitivity for rest after strenuous exercise, and for glucose and insulin, points in the same direction. It also fits in with the fact that continuously active muscles (such as those used in respiration) are usually not affected, and that acidosis, which inhibits protein synthesis, prevents attacks.

The assumption that protein synthesis is deranged may seem a bit farfetched, but ultrastructural analysis has revealed that the metabolic apparatus of the skeletal muscle cell is probably abnormal [2]. The idea that the attacks are caused by some form of autointoxication was formulated as early as 1891, but it remains difficult, and perhaps impossible, to prove such a postulated mechanism. Nevertheless, we believe that a high $\mathrm{P}_{\mathrm{Na}}$ scheme fits the data far more closely than does the low $\mathrm{P}_{\mathrm{K}}$ hypothesis.

\section{*Department of Cardiology, Division of Experimental Cardiology, and $†$ Department of Neurology \\ University Hospital Leiden \\ Leiden, Netberlands}

\section{References}

1. Cahalan MD: Modification of sodium channel gating in frog myelinated nerve fibres by centruroides sculpturatus scorpion venom. J Physiol (Lond) 244:51 l-534, 1975

2. Engel AG: Evaluation and content of vacuoles in primary hypokalaemic periodic paraiysis. Proc Mayo Clin 45:774-814, 1970

3. Hodgkin AL, Katz B: The effect of sodium ions on the electrical activity of the giant axon of the squid. J Physiol (Lond) 108:3777, 1949

4. Hofmann W, Smith RA: Hypokalaemic periodic paralysis studied in vitro. Brain 93:445-474, 1970

5. Layzer RB: Periodic paralysis and the sodium potassium pump. Ann Neurol 11:547-552, 1982

6. McComas AJ, Mrozek K, Bradley WG: The nature of electrophysiologic disorder in adynamia episodica. J Neurol Neurosurg Psychiatry 31:448-452, 1967

7. Norris FH: Micropipette recording from human striated muscle. J Neurol 213:1-15, 1976

8. Riecker G, Bolte HD: Mebranpotentiale einzelner Skeletmuskel Zellen bei hypokalämischer periodischer Muskelparalyse. Klin Wochenschr 44:804-807, 1966 